\title{
Supervising Residents Treating Multiproblem Patients: Transformations of Therapeutic Narcissism
}

\author{
Susan J. Olson, MD \\ Medical College of Wisconsin \\ Valerie A. Westhead, MD \\ Medical College of Wisconsin \\ Jean M. Goodwin, MD, MPH \\ Medical College of Wisconsin
}

Follow this and additional works at: https://jdc.jefferson.edu/jeffjpsychiatry

Part of the Psychiatry Commons

Let us know how access to this document benefits you

\section{Recommended Citation}

Olson, MD, Susan J.; Westhead, MD, Valerie A.; and Goodwin, MD, MPH, Jean M. (1988) "Supervising Residents Treating Multiproblem Patients: Transformations of Therapeutic Narcissism," Jefferson Journal of Psychiatry. Vol. 6 : Iss. 1 , Article 3.

DOI: https://doi.org/10.29046/JJP.006.1.001

Available at: https://jdc.jefferson.edu/jeffjpsychiatry/vol6/iss $1 / 3$

This Article is brought to you for free and open access by the Jefferson Digital Commons. The Jefferson Digital Commons is a service of Thomas Jefferson University's Center for Teaching and Learning (CTL). The Commons is a showcase for Jefferson books and journals, peer-reviewed scholarly publications, unique historical collections from the University archives, and teaching tools. The Jefferson Digital Commons allows researchers and interested readers anywhere in the world to learn about and keep up to date with Jefferson scholarship. This article has been accepted for inclusion in Jefferson Journal of Psychiatry by an authorized administrator of the Jefferson Digital Commons. For more information, please contact: JeffersonDigitalCommons@jefferson.edu. 


\title{
Supervising Residents Treating Multiproblem Patients: Transformations of Therapeutic Narcissism
}

\author{
Susan J. Olson, M.D. \\ Valerie A. Westhead, M.D. \\ Jean M. Goodwin, M.D., M.P.H.
}

\section{INTRODUCTION}

While much of the literature on psychotherapy supervision focuses on teaching psychotherapeutic techniques, most residents and supervisors realize that there is another agenda: making the often drained and narcissistically injured therapist feel better. The beginning therapist's self-esteem is especially vulnerable to injury because most psychiatric residents have "heavily committed themselves to a field of endeavor for which . . . they are relatively untested" (1). Coupled with this, they are often assigned the most difficult and demanding patients, those with narcissistic disorders who are unable to soothe themselves. Both Searles (2) and Balint (3) describe the barrage of countertransferences usually experienced by therapists treating such patients; these can be overwhelming for the new therapist struggling to develop a professional identity. Discussion of process and countertransference issues is often insufficient to the task of helping the resident maintain the positive self-regard which is essential to the development of adequate empathy for these patients.

However, it has been difficult to find the vocabulary adequate to describe this important supportive function of supervision. Residents complain about supervision degenerating into therapy when they sense discussions in supervision shifting from technical issues to personal feelings about patients, and residents feel they are being diagnosed (1). Supervisors correctly contend that residents feel better about themselves and their work as they learn more facts and techniques. However, until these techniques can be mastered over many months and years, the resident looks to the supervisor to help anchor an often floundering self-esteem.

This paper advances the language of narcissism as a possible common meeting ground for both residents and supervisors attempting to discuss this

Dr. Olson is an Assistant Clinical Professor at the Medical College of Wisconsin, Department of Psychiatry and Mental Health Sciences; she was a fourth year resident when the paper was written.

Dr. Westhead is Chief Resident of Psychiatry, Medical College of Wisconsin, Department of Psychiatry and Mental Health Sciences.

Dr. Goodwin is Professor of Psychiatry and Director of Joint Academic Programs, Medical College of Wisconsin and Milwaukee County Mental Health Complex. 
crucial area. The classic paper by Heinz Kohut, "Forms and Transformations of Narcissism" outlines five healthy aspects of narcissism: creativity, empathy, acknowledgement of finiteness, humor, and wisdom (4). In our experience, utilization of these developmental phenomena, whether in supervision or in the treatment hour, tends to lighten the load for the therapist. Narcissism also seems an appropriate vocabulary because patients who have difficulty with regulating their self-esteem are so expert at inflicting similar injuries, having learned this through their own narcissistic suffering. We also know that supervision is a place where the central themes occurring in treatment are replayed and displaced in what has been called "parallel process" in the psychoanalytic literature (5). It seems reasonable to think that a successful supervisory experience allows narcissistic injuries to be recognized, soothed, and prevented. Since this is the task of the therapist as well, the supervisor is also modeling techniques that can be used by the resident in the treatment hours.

Kohut's paper begins with a discussion of the transformations of infantile narcissism into its mature forms and its contributions "to health, adaptation, and achievement" (4). This healthy narcissism is the source of the beginning therapist's ambitions and ideals. It is these ambitions and ideals, and the resident's inevitable failure to live up to them, that must be discussed and understood in supervision and used to develop treatment plans that set reachable goals and assign do-able tasks.

In the body of this paper we will review Kohut's paper using clinical examples to illustrate its application to supervision. The idea for using these transformations in supervision came out of a conjoint supervisory experience involving two residents, each dealing with a very complicated case. One patient, the victim of incest with both her father and an older brother, had a history of multiple hospitalizations and multiple suicide attempts. In addition, she suffered from anorexia and bulimia, and frequently developed severe electrolyte imbalances. She met diagnostic criteria for major depressive disorder, anorexia nervosa, bulimia and borderline personality disorder. The resident often found therapy with this patient to be an endless struggle to try to keep the patient alive. The other patient, also a sexual abuse victim, had a long history of outpatient treatment dealing with bizarre perversions, multiple somatic complaints and manifested multiple personality fragments. In addition, EEG's showed bilateral temporal lobe abnormalities. He met diagnostic criteria for atypical dissociative disorder and organic personality disorder. The resident working with this patient frequently felt the patient needed her simply as an object to be emotionally abused and sexually harrassed in a repetition of what the patient himself had experienced as a childhood sexual abuse victim.

In the beginning phases of the supervisory experience, there was uncertainty about how the treatment plans for these two patients might be related. However, it became clear that the first step in supervision with both residents was to clarify the severity of these patients' narcissistic needs. At that point, it became possible for the residents to learn how to manage these patients' 
difficulties. The resulting evolution of each resident's ambitions and idealism began to be reflected in slow improvements by the patients. In reviewing the work in supervision and in the treatment hours, it became clear that Kohut's five mature transformations of narcissism had been used extensively in dealing with problems as they arose. We will use these examples to support our position that the language of narcissism can be a useful bridge between residents and advisors in supervision.

\section{CREATIVITY}

Kohut's first transformation is creativity in which narcissism participates as a "spur" driving the creative individual toward success and acclaim. When an individual is using narcissistic energy in this creative mode there is "less psychological separation from surroundings," and the relationship of creator to the evolving creation is more akin to the "schizoid and the childlike" in the "indistinctness of internal and external." Kohut attributes the "childlike freshness and simplicity" of creative scientific and artistic discoveries to the enhanced awareness of self and surroundings in which the creator's work becomes a "transitional object" invested with "transitional narcissistic libido." In other words, it becomes an extension of the creator's own mind (4).

Such a creative investment of healthy narcissistic energies is often required of the beginning therapist when working with multi-problem patients who have difficulty regulating their own self-esteem. So much is this the case, that just as the patient uses the therapist as a transitional object, a necessary step to developing mature object relations, so too, the patient becomes for the therapist an all-encompassing transitional project in developing therapeutic skills. The development of such skills is the focus of creative energy, thought, time and love. Supervision of residents in a vulnerable relationship with a transitional patient-object often requires attention to the imprecise, i.e., regressive, overidentified styles of thinking that can impair therapeutic judgement. However, the supervisor must also appreciate that the most creative interventions flow from this morass of cloudy thinking.

For example, the severely suicidal female patient called her therapist one night. The patient thought she might be having a miscarriage and was acutely frightened. The patient rejected the therapist's first two sensible suggestions to go to the Emergency Room or the Psychiatric Crisis Center. At that point, the resident, feeling overwhelmed by the patient's inability to follow rational suggestions, recalled that the patient's pregnancy was the result of her having been raped and suggested that the patient go to the local battered women's shelter.

At the shelter, the patient worked seriously for the first time on the incestuous relationship with her father which had kept her in constant fear of impregnation or genital damage. After working in groups of women with similar problems, she began to discuss these memories and feelings spontaneously in 
individual treatment as well. Previously, the patient had repeatedly refused to join an adult incest victims group. After less than one week in the shelter, the patient returned home. After spending most of the previous two years in psychiatric hospitals, the creative approach used by the resident enabled the patient to maintain a hospitalization-free record for the entire year of outpatient therapy.

\section{EMPATHY}

The second transformation Kohut describes is empathy, which is related to creativity because it involves the capacity to tolerate partial dissolution of the "I-you barrier." The empathic individual is able to imagine another's inner experience in a "single act of apperception." This may be viewed as similar to the small child's "perceptual merging with mother's face," in which the child gains direct and immediate access to mother's emotional state. Kohut notes that empathy is one of the earliest forms of cognition which later becomes superceded in adult life by nonempathic, rational forms of cognition (4).

The beginning therapist in supervision is encouraged to use this intuitive mode of understanding regressed patients. However, there may be a powerful resistance on the part of the therapist to using this tool. An individual may resist the "acknowledgement of unconscious knowledge about others" (4), when such knowledge contains a frightening awareness of a patient's sadomasochism and potential destructiveness to self and others. The tendency of both of these residents to occasionally view their patients as manipulative was understood as stemming from needs to block out their empathic appreciation of the desperately chaotic and realistically dangerous states of their patients' inner lives. During the course of supervision with the male patient, the beginning therapist feared her supervisor was "going crazy" when she suggested that the resident needed to find a way to identify empathically with the patient's feelings enough to become his advocate if treatment was to succeed. To the resident at that point, it seemed that empathizing in this way would only promote further regression. Only after several months did it become clear that a treatment plan which included meeting some of the patient's emotional needs was actually decreasing his acting out. At this point, the resident acknowledged her fears to the supervisor that allowing empathic contact with this patient would lead to her becoming a victim of the patient's sexual harassment and perhaps drive her into a shared psychosis. Only by projecting this fear onto the supervisor, who was after all at a safe distance, was the therapist slowly able to increase therapeutic intimacy.

Over-control in a treatment session is often a sign that the empathic tie has been broken. This same patient demanded treatment for a "baby" self-fragment who wished to wear diapers to his therapy sessions. The resident responded by forbidding not only the behavior, but all discussion of sexual topics in her fear that the patient might act out his sexual fantasies of masturbating openly in 
treatment and of "spanking" and "being spanked" by his therapist. Only when supervision allowed the resident to fully experience her own fear of being with this patient, was she able to speculate about his terror of being with her. At that point, she was able to correctly interpret the patient's sexual threats as a distancing maneuver.

The patient's struggle to develop trust in the therapist's empathy is mirrored by the resident's struggle to develop trust and spontaneity in supervision. The resident treating the young female patient finally dared to admit that she perceived the supervisor as intellectually stimulating and interesting, however, often not overly useful when trying to deal with the crises and problems of her patient's day-to-day life. Discussion of this in supervision led to the hypothesis that perhaps her patient felt much the same way: appreciative of the work in therapy but feeling it was not helpful or practical when dealing with her life. When this interpretation was shared, the patient agreed with some relief. She valued the new sense of aliveness to and awareness of feelings within the therapy sessions, but felt that this made it all the more difficult for her to function between sessions.

\section{ACKNOWLEDGEMENT OF FINITENESS}

Kohut describes the third transformation, the "capacity to contemplate [one's] own impermanence" as follows: "Man's capacity to acknowledge the finiteness of his existence, and to act in accordance with this painful discovery, may well be his greatest psychological achievement . . . based on the relinquishment of emotional infantilism, and abandonment of even a trace of the narcissistic insistence on the omnipotence of the wish; it expresses the acceptance of realistic values" (4).

In dealing with the narcissistically disordered patient, the therapist will perish if she tries to address, much less meet, all of the patient's demands and needs. The long-term persistence of frightening and disabling symptoms is difficult for the therapist to observe without feeling a failure. Even harder to accept is the fact that appropriate and ultimately helpful interventions may result in transient worsening of the patient's symptoms. This is the result of the patient continuing to use her customary and pathologic ways to reduce tension. However, these methods work less well and the patient has not yet developed alternate methods that can be more successful.

The young female patient often responded to stressful therapy sessions, where her anger and frustration about her incestuous relationships surfaced, by cutting or burning herself, or by staying awake all night. On one occasion the patient felt she had insulted her therapist during the hour and called two hours later to apologize, stating she had eaten a large meal then forced herself to vomit because of her guilt. The therapist responded by stating she wished the patient could have verbalized her concerns in the session or over the phone without hurting herself in this way. The supervisory group discussed the therapist's sense 
of failure and anger at the patient for making the therapist feel a party to her self-destructive behavior. It was also important to discuss in supervision how the patient was using old tactics to resolve conflicts, but less successfully, and it would take time for consistent interpretations regarding the patient's poor self-esteem and distrust of the therapist to aid the patient in finding alternate coping skills.

With this patient, the therapist needed to continually recall the persistent and severe self-destructive career that preceded treatment, and remind the patient of this from time to time so that stepwise improvement could be perceived. For example, on one occasion the therapist expressed a sense of failure because the patient continued to take overdoses when feeling extremely depressed and angry. However, it was noted that the patient was now using benzodiazepines in relatively low doses (three to five times therapeutic dosage) for this activity. Previously, she had overdosed on antidepressant medications and required several admissions to the intensive care unit because of cardiac dysrhythmias.

In a similar vein, the young male patient continually complained of bizarre somatic problems which in the past had led to the patient making frequent visits to emergency rooms. It was important to understand these somatic complaints as a means in which the patient communicated with his therapist. To facilitate therapy, a treatment team approach was developed to help the primary therapist coordinate his treatment and diminish his inappropriate use of medical services. It was also the result of acknowledging the finite therapeutic limits of two therapy sessions per week. The team, which met together monthly to coordinate their efforts, included the patient, the therapist, the supervisor, the other resident in the supervision (who filled in for the primary therapist during absences), an occupational therapist, and the patient's internist.

This patient usually presented a kaleidoscopic mixture of self-destructive fantasies and aggressive sexual fantasies that frequently made it impossible to determine what the problems were, let alone know how to treat them. During a team staffing immediately prior to his therapist's vacation, the patient claimed to have borrowed a gun and said he planned to render himself a paraplegic by shooting himself in the spine. Although this fantasy represented fascinating and obscure multiple determinants, the team realistically focused on the goal of maintaining the patient's safety. When confronted with a recommendation for hospitalization, the patient admitted that he had been lying about the gun, and with support, he was able to express some anger and frustration towards his therapist for leaving him.

Both these patients had constant self-destructive thoughts and impulses and poor self-control. This raised the uncomfortable possibility that one or the other might successfully commit suicide while in treatment with their respective residents. Recognizing the real limitations of a therapists' ability to prevent this was openly discussed, and both beginning therapists were able to imagine in 
detail what this would do to their professional self-esteem (6). This open discussion permitted ventilation of the residents' fears and countertransference hatred (7), and allowed them to be more calmly objective when their patients were in a suicidal crisis.

\section{HUMOR}

The capacity for humor is Kohut's fourth mature transformation of narcissism. This sense of humor presents itself not as "a picture of grandiosity and elation but that of a quiet inner triumph with an admixture of undenied melancholy" (4). For the beginning psychotherapist, humor appears in the capacity to appreciate the ironic aspects (8) of trying to deal with these severely troubled patients and their myriad of problems. This is not attained by laughing at the patient, but by laughing on a more cosmic level at the incredibly complex problems they present, and the apparent futility of their lives.

Humor in the supervisory hours allowed not only emotional discharge, but also recognition of the therapeutic limitations of the residents in dealing with these complicated and emotionally taxing cases. The young male patient frequently presented such a garbled version of what was going on in his life mingled with details of his fantasies of sexually abusing his therapist, that the absurdity of it on occasion provoked his therapist to smile during the therapy hours. This made him feel that she was laughing at him. In supervision it became clear that the therapist was defending herself against some real fears of the patient, but predominantly, it expressed her realization of how hopelessly complicated the patient's problems were. One supervisory hour produced the metaphor that the patient was like an onion with one amorphous layer after another slowly being peeled away, revealing ever deeper layers of his pathology. Taking the analogy further, the treatment was described as attempting to work "with an entire bag of onions. With a hole in the bag; several holes."

This patient also aroused animosity by always being under foot in the waiting area of the clinic, hours before his appointment, where he frequently tried to talk to members of his treatment team and update them on current events in his life. This behavior was often irritating to both his primary therapist, and the other resident who covered for her when she was away. However, the supervisor remained unperturbed when approached, which was puzzling to the residents. One day in the supervision, the primary therapist described feeling he was following her about like a tag-along younger sibling interrupting with demands for care. The supervisor's metaphor for this behavior, likened him to a hyena, always on the edge of the human encampment. This exchange of metaphors allowed the residents to develop a deeper understanding of the patient's difficulties as well as an appreciation of the irony of his situation. In the aftermath, the residents were more direct with the patient about what their limits were, as well as more understanding of this patient's realistic needs for 
frequent brief base-touching with his caretakers as part of the process of his learning to soothe himself.

\section{WISDOM}

Wisdom, as Kohut's final transformation, is a "stable attitude" involving the integration of cognitive function with a mature world view comprised of humor, and the acceptance of finite limitation in a firmly cathected value system (4).

The supervisor provides a model to the beginning therapist in the exercise of maturity and wisdom in handling patients with narcissistic disorders. The need for this type of perspective is most acute when the patient is attempting to lure the therapist into a transference re-enactment. In discussing one such transference struggle, the resident was able to tease out multiple strands of meaning in her anorexic patient's seemingly ingenuous question: "Do I look thin?" In supervision, the precarious double bind within this question became apparent. If the therapist answered "yes," the patient could construe this as a repetition of scenes between herself and her mother in which her mother was often overly critical and punitive, in part because of her envy at the developing beauty of her adolescent daughter. However, if the therapist should answer "no" and deny the obvious reality of her patient's precipitous weight loss which if not actively addressed could be life threatening, she would repeat the mother's original neglect and inability to see the patient accurately. Either answer would certainly escalate the patient's self-destructive anorexic behavior.

Appreciation of the double binds which these multiproblem patients imposed upon their therapists enhanced the residents' appreciation of the complexity of the patients' communications and of the subtleties of the treatment task. When the fragmented young man asked his therapist to provide him a recommendation to work in a volunteer position with hospitalized children, he was expressing his aspirations to get better, hold a job, and have mature satisfactions in life. However, he was also trying to take his own childish alter ego to a children's hospital for play therapy. He was also testing whether his therapist would protect real children from his present perversions in a way that he had not been protected as a child.

For physicians trained to seek the "right" answer, a "wisdom" perspective can be frustrating. How can one explain to one's self, one's patients, or to one's colleagues that the "right" answer is that there is no "right" answer? On one occasion the supervisor related a recent dream of hers in which a trainee complained that the supervisor had not taught a single new idea in an entire year of supervision. "Ideas!" scoffed the supervisor in her dream, "Ideas are the least of what I have to teach." In the context of the supervision, this dream expressed the supervisor's view that her task, and the task of the therapists, did not involve ending an argument or conflict by selecting the "right" idea, but rather, her task 
was to learn to comment on these double bind situations and reflect upon them until a new integration of seeming opposites became possible.

\section{SUMMARY}

In this paper we have proposed that the language of narcissism may be a useful tool for effective supervision of narcissistically disordered patients with impaired self-esteem. In reviewing Heinz Kohut's description of five healthy transformations of narcissism, we found a useful vocabulary for describing our experience in a conjoint supervisory setting dealing with two very complicated patients. By understanding and discussing the healthy narcissistic component of the residents' ideals and ambitions that encouraged them to pursue a career in psychiatry, and addressing disastrous therapeutic hours that made them despair of ever realizing their ambitions and ideals, supervision did more than just instruct them in psychotherapeutic technique; it helped them feel better. The less drained residents were, the more able they were to be effective in dealing not only with multiproblem patients, but also with all of the demands of the psychiatric residency and other patients in treatment.

In summary, we have used Kohut's paper on the "Forms and Transformations of Narcissism" to provide a framework for supervision of the multiproblem patient. Encouraging the free use of healthy narcissism at an especially vulnerable phase of training seemed to help residents on many levels. We have elaborated, with clinical examples, the supervisor's modeling and strengthening of the beginning therapist's use of creativity and empathy, acceptance of finite limits, and development of humor and wisdom. Ultimately, supervision must be grounded in the ambitions and ideals of both resident and supervisor. These should include both a mature acceptance of the narcissistic injuries which multiproblem patients frequently inflict on themselves and others, as well as the challenge to creative transformations of therapeutic narcissism which they provide for the novice therapist.

\section{ACKNOWLEDGEMENT}

Special acknowledgement to William Offenkrantz, M.D., for his additional insight and assistance with this manuscript.

\section{REFERENCES}

1. Spiegel D, Grunebaum H: Training versus treating the psychiatric resident. Am J Psychother 1977; 31:618-625

2. Searles H: The countertransference with the borderline patient, in Essential Papers on Borderline Disorders-One Hundred Years at the Border. Edited by Stone MH. New York, New York University Press, 1986, pp 498-525 
3. Balint M: The basic fault, in Essential Papers on Borderline Disorders-One Hundred Years at the Border. Edited by Stone MH. New York, New York University Press, 1986, pp 385-409

4. Kohut H: Forms and transformations of narcissism. J Am Psychoanal Assoc 1966; 14:243-272

5. Sachs D, Shapiro S: On parallel processes in therapy and teaching. Psychoanal Quart $1976 ; 45: 394-415$

6. Schnur DB, Levin EH: The impact of successfully completed suicides on Psychiatric Residents. J Psych Ed 1985; 9:127-136

7. Maltsberger JT, Buie DH: Countertransference hate in the treatment of suicidal patients. Arch Gen Psych 1974; 30:625-633

8. Schafer R: The psychoanalytic vision of reality. Int J Psychoanal 1970; 51:279-297 